This item was submitted to Loughborough's Research Repository by the author.

Items in Figshare are protected by copyright, with all rights reserved, unless otherwise indicated.

\title{
Systemic BIM adoption: a multilevel perspective
}

PLEASE CITE THE PUBLISHED VERSION

https://doi.org/10.1061/(ASCE)CO.1943-7862.0002017

\section{PUBLISHER}

American Society of Civil Engineers

\section{VERSION}

AM (Accepted Manuscript)

\section{PUBLISHER STATEMENT}

This material may be downloaded for personal use only. Any other use requires prior permission of the American Society of Civil Engineers. This material may be found at https://doi.org/10.1061/(ASCE)CO.19437862.0002017.

\section{LICENCE}

All Rights Reserved

\section{REPOSITORY RECORD}

Murguia-Sanchez, Danny, Peter Demian, and Robby Soetanto. 2021. "Systemic BIM Adoption: A Multilevel Perspective”. Loughborough University. https://hdl.handle.net/2134/13252106.v1. 


\title{
Systemic BIM Adoption: A Multilevel Perspective
}

\author{
Danny Murguia¹, Peter Demian², Robby Soetanto ${ }^{3}$ \\ 1 Doctoral Researcher, School of Architecture, Building, and Civil Engineering, Loughborough University, \\ Loughborough, LE11 3TU, United Kingdom (corresponding author). Email: D.Murguia@lboro.ac.uk \\ 2 Reader in Building Information Management, School of Architecture, Building, and Civil Engineering, \\ Loughborough University, Loughborough, LE11 3TU, United Kingdom. Email: P.Demian@lboro.ac.uk \\ 3 Senior Lecturer in Construction Management, School of Architecture, Building, and Civil Engineering, \\ Loughborough University, Loughborough, LE113TU, United Kingdom. Email: $\underline{\text { R.Soetanto@lboro.ac.uk }}$
}

\begin{abstract}
:
Systemic innovations require multiple interdependent actors to change their practices simultaneously in order to realise the benefits of the innovation. Building Information Modelling (BIM) has been classified as a systemic innovation that is adopted by building projects, firms, and users. However, the slow diffusion of BIM in the Architecture, Engineering, and Construction (AEC) sector has maintained the gap between BIM visions and actual BIM practice. Some governments are planning to enact policies to promote BIM adoption in construction. However, in some countries, BIM adoption has already started with large construction organisations (i.e., the middle-out diffusion approach). To learn from previous experience and before enacting top-down interventions, policymakers require a model to stimulate systemic BIM adoption for entire supply chains with fragmented project and organisational structures. The current paper investigates systemic adoption of digital innovations in construction and is aimed at formulating a model of systemic BIM adoption (MSBA). Three primary datasets consisting of 133 BIM users, 30 chief executive officers, and 20 project managers were collected in Peru and collectively analysed using cross-classified multilevel modelling (CCMM). It was found that MSBA has five user-, three firm-, and two project-level factors, explaining $28 \%, 75 \%$ and $50 \%$ of variance in users' BIM adoption respectively. The proposed model would provide useful guidance for corporate decisionmakers and government policymakers to develop BIM-diffusion policies to accelerate adoption. It would also provide a useful practical implementation framework as the industry progresses towards a digital mode of working and could underpin further digitalisation of the sector worldwide.
\end{abstract}

Keywords: BIM adoption; user; firm; project coalition; systemic innovation, middle-out diffusion 


\section{Introduction}

Building Information Modelling (BIM) is defined as the set of technologies, processes, and policies adopted by users, firms, and projects to make decisions effectively across the project life cycle. BIM is revolutionising the Architecture, Engineering, and Construction (AEC) industry around the world. The global BIM movement is spreading from developed to developing countries (Jin et al. 2017). However, some scholars suggest that the diffusion of BIM has been slow and that BIM adoption across the project life cycle is yet to occur (Gu and London 2010; London et al. 2008; Manderson et al. 2015). BIM is intended to bring together all project partners, who will use the same information to design, build, and operate better projects. However, there is a significant gap between BIM visions and practice (Davies and Harty 2013). Notably, BIM is hardly used at the same level by all users and firms in a temporary project coalition. This uneven distribution of firm capabilities and user adoption hinders the desired outcome at the supply-chain level.

\subsection{BIM as a systemic innovation}

Systemic innovations are innovations that require multiple actors to change and align their practice simultaneously in order to achieve the benefits of the innovation (Taylor and Levitt 2004). To realise this potential, the set of innovations requires implementation from the earliest stages, intra-firm collaboration, and organisational authority to ensure integration (Slaughter 1998). BIM has been classified as a systemic innovation (Murphy 2014). Murguia et al. (2017) defined systemic BIM innovation as the set of BIM-related technologies, processes, and organisational innovations, which requires multiple firms and users to change their practices simultaneously. Davies et al. (2015) argued that BIM is a systemic innovation that is enacted and adopted by firms, projects, users, and institutional actors. Moreover, BIM is a systemic inter-firm innovation predicted to have a great impact on the efficiency of the construction process (Lindblad and Gustavsson 2018; Lindgren and Widén 2018).

Systemic BIM adoption requires users from different firms to change their inter- and intra- firm working practices. Hence, in this research, the user is placed at the centre of systemic BIM adoption. Adoption is ultimately in the hands of users who create, use, and exchange information, and then go on to make decisions using BIM. Nevertheless, at any point of time, users work for firms and on projects. As such, 
factors from the firm and project can influence users' BIM adoption. Thus, systemic BIM adoption is multi-layered and directly influenced by its immediate context, the firm, and the broader project context.

\subsection{The need for a model of systemic BIM adoption}

BIM has been adopted primarily for productivity improvement by individual organisations; consequently, it has not led to systemic change across the sector (Aksenova et al. 2019). The reasons for this could be explored more effectively in the holistic context of firms and users working in temporary coalitions.

Systemic innovations in construction have been studied through the perspectives of knowledge integration (Lindgren and Widén 2018), supply-chain-integration practices (Hall et al. 2018), the project manager's role (Lindblad and Gustavsson 2018), factors that influence diffusion (Lindgren and Emmitt 2017), and actors' needs (Singh 2014). However, the adoption of systemic innovations by the user is not yet well understood.

BIM-adoption research has yielded numerous competing models at the user, firm, and project levels. Whilst these models help to improve our understanding on BIM adoption, they suffer from several shortcomings: (1) Most diffusion models explain users' intention to adopt BIM rather than actual BIM practice; (2) They rarely measure adoption by members of the same firm or project coalition; (3) In some studies, data were obtained from participants who did not answer questions at the level appropriate to their own position. For example, users were asked about firm- or project-level factors, and decisionmakers were asked about user-level factors; (4) There is a lack of evidence regarding the effect of firmand project-level factors on users' BIM adoption; and (5) None of the previous models have holistically combined different analytical levels into a unified model to explain users' BIM adoption.

A model which is grounded on BIM adoption by the user, but accounts for contextual firm- and projectlevel factors, would be an original and valuable contribution. Therefore, a unified model is deemed to be a model of systemic BIM adoption (MSBA) which could assist decision- and policymakers in formulating strategies to accelerate users' BIM adoption in the industry. The overarching aim of this research is to develop a model that identifies the user-, firm-, and project-level factors that influence users' BIM adoption. First, from the literature, factors related to the user, firm, and project were identified. Second, three different data sets were carefully collected and analysed. Project-level data were collected from 20 project managers of BIM-enabled projects in Peru. Firm-level data were 
collected from 30 chief executive officers (CEOs) of architecture, engineering, and construction firms working on these projects. User-level data were collected from 133 professionals working simultaneously for these firms and projects. The value of these original datasets lies in the purposive data collection from an ecosystem of users, firms, and projects within an industry context. Third, the empirical data were analysed using cross-classified multilevel modelling (CCMM) which allows for combining datasets at different analytical levels such as individuals simultaneously grouped into firms and into projects. As such, the variability of the outcome variable (users' BIM adoption) could be explained by factors at the user, firm, and project levels. Finally, theoretical and managerial implications are discussed.

\section{Existing BIM adoption models}

This section presents a critical review of existing BIM-adoption models at the user, firm, and project levels which informed the development of the MSBA.

\subsection{User-level adoption models}

BIM-adoption models at the user level have become prominent since 2014. Studies have been conducted in China (Ding et al. 2015), India (Ahuja et al. 2016), South Korea (Kim et al. 2016; Park et al. 2019), United Kingdom (Howard et al. 2017), Australia (Sargent et al. 2012), Thailand (Ngowtanasawan 2017), Malaysia (Enegbuma et al. 2016), and the United States (Lee and Yu 2016). Research has mainly focused on BIM adoption by design and construction professionals. Moreover, the outcome variable of most studies is the 'Intention to Adopt BIM' (Ding et al. 2015; Kim et al. 2016; Park et al. 2019; Sargent et al. 2012; Son et al. 2015). Nonetheless, other authors have examined actual BIM practice (Howard et al. 2017; Ngowtanasawan 2017).

It is also noteworthy that some studies measure firm-level variables at the user level. For example, Park et al. (2019) found that perceived cost is not a predictor of a user's intention to adopt BIM. However, users do not have decision-making influence regarding a firm's expenditures. Thus, this variable is not measured at an appropriate analytical level. Conversely, other studies have analysed user-level variables collected from decision-makers. Lee and Yu (2016) presented a user and firm BIM-adoption model for construction organisations. Yet the study surveyed project directors. Therefore, the study captured project directors' perceptions of users' BIM adoption, rather than those of the actual users. 


\subsection{Firm-level adoption models}

BIM-adoption models at the firm level focus on small and medium enterprises (SMEs) (Hong et al. 2019a, b; Hosseini et al. 2016), architecture firms (Ahmed and Kassem 2018), engineering firms (Cao et al. 2016), construction firms (Bosch-Sijtsema et al. 2017; Hong et al. 2019a), and all types of firms (Chen et al. 2019). Studies have been conducted in China (Hong et al. 2019a), Australia (Hong et al. 2019b), Turkey (Ozorhon and Karahan 2017), Sweden (Bosch-Sijtsema et al. 2017), United Kingdom (Ahmed and Kassem 2018), and the United States (Lee et al. 2015). As with user-level models, there are more studies of the intentions to use BIM than the firm's actual BIM use (Hong et al. 2019a, b). However, some other studies set out to measure actual BIM use (Cao et al. 2016; Chen et al. 2019).

Hosseini et al. (2016) presented a model of BIM adoption for SMEs in Australia. In the study, $80 \%$ of the respondents were project directors. Other studies, however, collected data from end-users instead of senior executives (Cao et al. 2017; Lee et al. 2015). Hong et al. (2019b), despite adopting the firm as their unit of analysis, did not report the job positions of the 80 respondents within their firms.

\subsection{Project-level adoption models}

Fewer studies were encountered of BIM-adoption models at the project level. The foci of such studies are the effect of client and environmental factors on BIM applications (Cao et al. 2014), 4D performance impact (Gong et al. 2019), project performance (Franz and Messner 2019), and the decision to adopt BIM in refurbishment projects (Okakpu et al. 2019). Nonetheless, these studies did not incorporate project-level variables that would potentially influence users' BIM adoption within the project coalition.

\section{The proposed model of systemic BIM adoption}

The design or construction professional working for a firm and on a project is the unit of analysis in MSBA. User-level variables might explain variation between users. Firm-level factors might explain the variation between firms in users' BIM adoption. Similarly, project-level factors could explain the variation between projects in users' BIM adoption. Therefore, MSBA examined the cross-level relationships of macro-level factors (firm and project) and micro-level outcomes (individual users' BIM adoption). Table 1 summarises the proposed factors in each analytical level found in the literature. Figure 1 shows the proposed research model. The dashed lines represent the boundaries between analytical levels. Arrows 
intersecting the dashed lines represent cross-level hypotheses. Table 2 summarises the hypothesised

relationships. The proposed model extends user-level models by investigating the effect of firm- and

project-level factors on users' BIM adoption. Moreover, there is a lack of studies investigating the effect

of firm- and project-level factors on users' BIM adoption. This research aims to fill this gap.

Table 1. Factors influencing users' BIM adoption by analytical level, from the literature.

\begin{tabular}{|c|c|}
\hline Level & Factor \\
\hline \multirow[t]{4}{*}{ User } & $\begin{array}{l}\text { Performance } \\
\text { Expectancy } \\
\text { Effort Expectancy }\end{array}$ \\
\hline & Social Influence \\
\hline & Behavioural Intention \\
\hline & Facilitating Conditions \\
\hline \multirow[t]{4}{*}{ Firm } & Firm Type \\
\hline & Firm Size \\
\hline & $\begin{array}{l}\text { Technology readiness } \\
\text { (optimism) } \\
\text { Technology readiness } \\
\text { (innovativeness) } \\
\text { Top-management } \\
\text { support }\end{array}$ \\
\hline & $\begin{array}{l}\text { Firm's facilitating } \\
\text { conditions }\end{array}$ \\
\hline
\end{tabular}

Firm's BIM Adoption Firms exhibit a mixture of competences, capacity, resources, culture and attitude to compete in the market. Therefore, employees deploy intra- and inter-firm BIM practices

Project System Integrator

Diffusion dynamic

The system integrator steers the innovation process, aligns objectives and overcomes individuals' and organisations' resistance. The system integrator (Client vs. Contractor) might explain the variation between projects in users' BIM adoption In the client-led approach, the client or owner requires BIM adoption, while in the supply-lead approach, the general contractor leads BIM implementation in the project. The diffusion dynamic (Client-led vs. Supplier-Led) might explain the variation between projects in users' BIM adoption

Authorship of BIM Models BIM models can be maintained in-house or outsourced to service providers, a decision made early in the project. However, the author of BIM models (Consultant vs. In-House) might explain the variation between projects in users' BIM adoption

Governance Mode The market mode is a self-regulated BIM process in which diffusion happens in a co-learning process without a mandate. The question remains whether a mandate or a co-learning process facilitates or deters users' BIM adoption.

Project-Coalition Some firms are unable or unwilling to engage with BIM. If one Technology Capability or more firms are not prepared to use BIM, or they use CAD and BIM simultaneously, it could affect users' BIM adoption within the project coalition.

\section{Sources}

(Davies and Harty 2013; Howard et al. 2017; Sargent et al. 2012; Venkatesh et al. 2003)

(Gu and London 2010; Kim et al. 2016)

(Ayinla and Adamu 2018; Dainty et al. 2017; Peansupap and Walker 2005; Poirier et al. 2015) (Foroozanfar et al. 2017; Liljander et al. 2006;

Parasuraman 2000)

(Ahuja et al. 2016; Lee and Yu 2016; Park et al. 2019; Sargent et al. 2012) (Ahuja et al. 2016; Howard et al. 2017; Sargent et al. 2012; Son et al. 2015; Venkatesh et al. 2003)

(Ahmed and Kassem 2018; Mahamadu et al. 2017)

(Erbil et al. 2013; Harty 2008; Lindblad and Gustavsson 2018; Renier and Volker 2008)

(Eadie et al. 2015; Elmualim and Gilder 2014; Lindblad and Guerrero 2020; Linderoth 2010; Poirier et al. 2015)

(Fountain and Langar 2018; Gu and London 2010; Kim et al. 2016)

(Keast and Hampson 2007)

(Dainty et al. 2017) 
Project-Coalition Collaboration Level
Collaboration can be defined as the commitment of actors to the attainment of common project objectives by means of effective and transparent communication. If one or more firms are not fully engaged in the collaborative process, it could affect users' BIM adoption within the project coalition.
(Arayici et al. 2011; Eadie et al. 2013; Mahamadu et al. 2019)

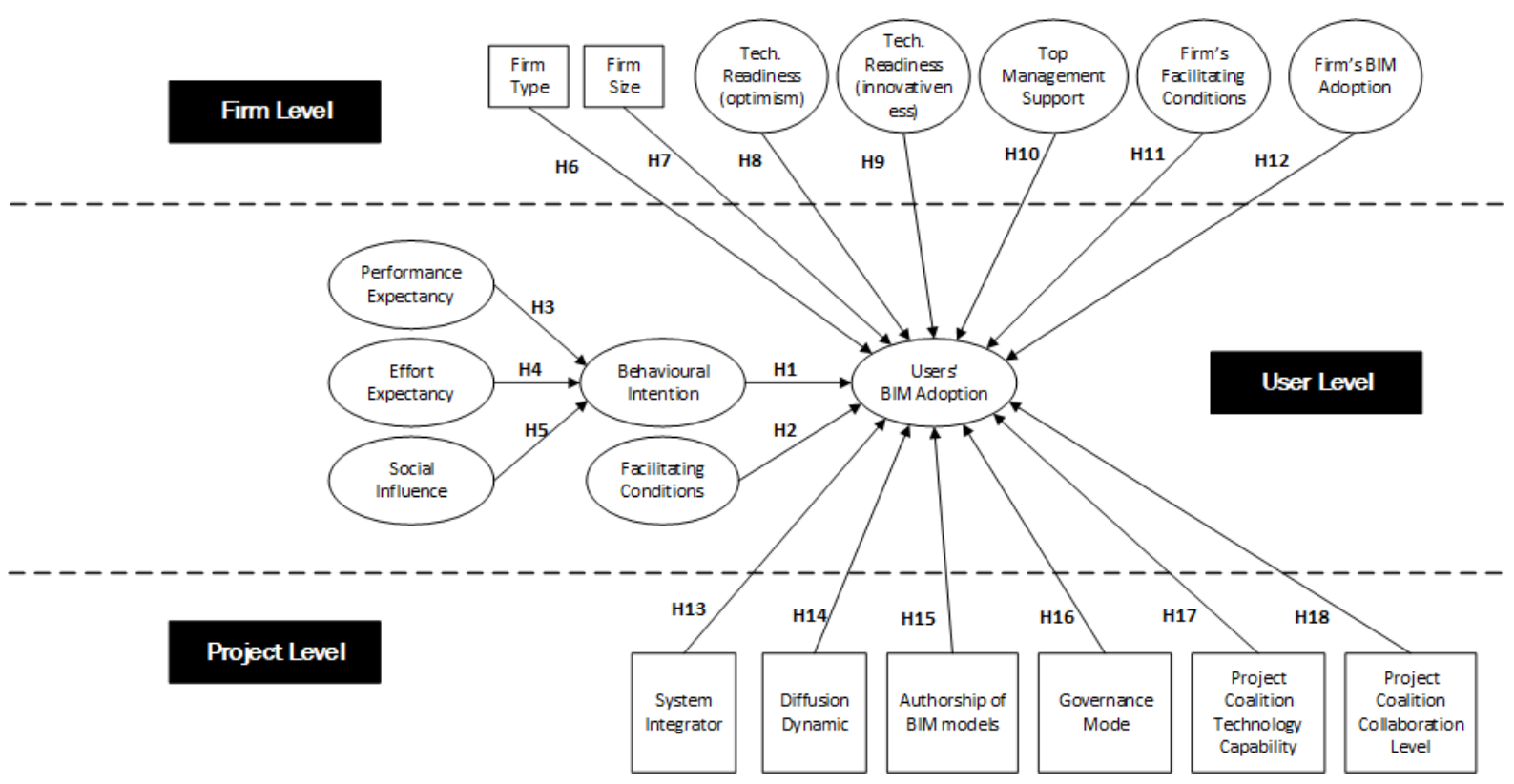

Fig. 1. Research Model. Ovals are multi-item factors; rectangles are observed variables.

Table 2. Hypotheses in the research model

$\begin{array}{ll}\text { Number } & \text { Hypothesis } \\ \text { H1 } & \text { 'Behavioural Intention' will have a significant influence on users' BIM adoption } \\ \text { H2 } & \text { 'Facilitating Conditions' will have a significant influence on users' BIM adoption } \\ \text { H3 } & \text { 'Performance Expectancy' will have a significant influence on 'Behavioural Intention' } \\ \text { H4 } & \text { 'Effort Expectancy' will have a significant influence on 'Behavioural intention' } \\ \text { H5 } & \text { 'Social Influence' will have a significant influence on 'Behavioural Intention' } \\ \text { H6 } & \text { 'Firm Type” will have a significant influence on users' BIM adoption } \\ \text { H7 } & \text { 'Firm Size" will have a significant influence on users' BIM adoption } \\ \text { H8 } & \text { 'Technology Readiness (optimism)' will have a significant influence on users' BIM adoption } \\ \text { H9 } & \text { 'Technology Readiness (innovativeness)' will have a significant influence on users' BIM adoption } \\ \text { H10 } & \text { 'Top-Management Support' will have a significant influence on users' BIM adoption } \\ \text { H11 } & \text { 'Firm's Facilitating Conditions' will have a significant influence on users' BIM adoption } \\ \text { H12 } & \text { 'Firm's BIM Adoption' will have a significant influence on users' BIM adoption } \\ \text { H13 } & \text { The 'System Integrator' will have a significant influence on users' BIM adoption } \\ \text { H14 } & \text { The project's 'Diffusion Dynamic' will have a significant influence on users' BIM adoption } \\ \mathrm{H} 15 & \text { The 'Authorship of BIM Models' will have a significant influence on users' BIM adoption } \\ \mathrm{H} 16 & \text { The 'Governance Mode' will have a significant influence on users' BIM adoption } \\ \mathrm{H} 17 & \text { The 'Project-Coalition Technology Capability' will have a significant influence on users' BIM adoption } \\ \mathrm{H} 18 & \text { The 'Project-Coalition Collaboration Level' will have a significant influence on users' BIM adoption }\end{array}$




\section{Research method}

A quantitative approach was selected as the primary methodology in view of the defined objectives of the study. Cross-sectional questionnaire data were used to test the research model shown in Figure 1. If the sample is deemed to be representative, findings become applicable to the larger population. Three different questionnaires were designed in order to collect data at three different analytical levels. Therefore, our targeted respondents were project managers of BIM-enabled projects, CEOs or senior executives of the firms working for these projects, and design and construction professionals working for these firms and projects. The sampling strategy was purposively nested, as we aimed to investigate cross-level relationships; thus, the interdependence and the group functioning of these professionals in a hierarchical system is of focal interest.

\subsection{Cross-classified modelling}

Cross-classified modelling can be used to analyse complex data when lower units belong to pairs of higher-level units (Leckie 2013). This is the nature of users' BIM-adoption data, as users work for a firm and on a project simultaneously, as shown in Figure 2. Therefore, BIM users are nested within firms and are separately nested within projects. Firms and projects are not typically nested within one another, as not all BIM users from the same firm work on the same project. Thus, firms and projects are crossed with one another, with each user potentially belonging to a combination of firm and project.

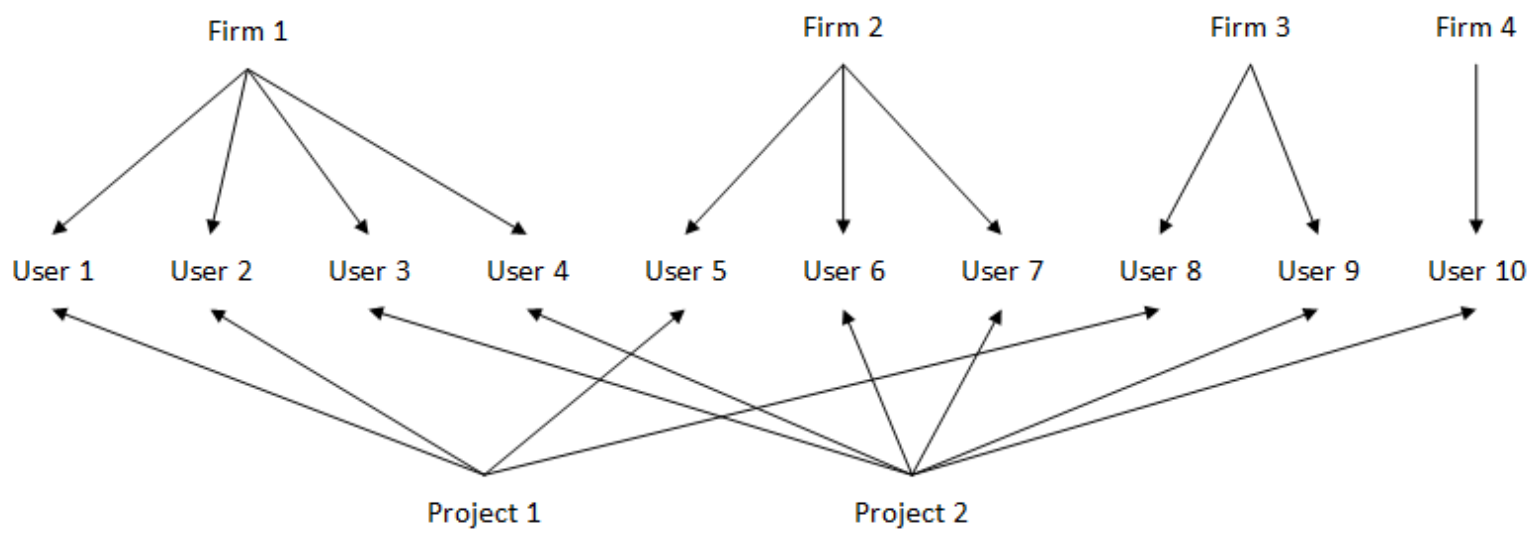

Fig. 2. Cross-classified structure. 
The cross-classified model breaks down the outcome-variable variance into separate variable components associated with the higher cross-classified levels and lower user levels. The model can be written as shown in Eq. (1) (Leckie 2013):

$y_{i j k}=\beta_{o}+v_{k}+\mu_{j}+\varepsilon_{i j k}$, with $v_{k} \sim N\left(0, \sigma_{v}^{2}\right), \mu_{j} \sim N\left(0, \sigma_{\mu}^{2}\right), \varepsilon_{i j k} \sim N\left(0, \sigma_{\varepsilon}^{2}\right)$

where $y_{i j k}$ is the BIM adoption of user $i$ who works for firm $j$ and project $k$; $\beta_{o}$ is the mean score across projects and firms; $v_{k}$ is the effect of project $k ; \mu_{j}$ is the effect of firm $j$; and $\varepsilon_{i j k}$ is the user-level residual error term. Therefore, the total variance of the outcome variable $y_{i j k}$ is split into the difference between users (between-user variance $\sigma_{\varepsilon}^{2}$ ), differences between firms (between-firm variance $\sigma_{\mu}^{2}$ ), and differences between projects (between-project variance $\sigma_{v}^{2}$ ). The firm and project effects on the total variance can be measured with the intra-class correlation coefficient (ICC) as shown in Eq. (2) and Eq.

(3) (Leckie 2013). The ratio of the firm-level variance to the total variance is ICC $\mu$ and can be expressed as follows:

$$
I C C_{\mu}=\frac{\sigma_{\mu}^{2}}{\sigma_{\varepsilon}^{2}+\sigma_{\mu}^{2}+\sigma_{v}^{2}}
$$

The ratio of the project-level variance to the total variance is ICC $v$ and can be expressed as follows:

$$
I C C_{v}=\frac{\sigma_{v}^{2}}{\sigma_{\varepsilon}^{2}+\sigma_{\mu}^{2}+\sigma_{v}^{2}}
$$

ICC ranges from 0 (no inter-group differences) to 1 (no differences between users in the same group). A low ICC value means high variability within groups and low variability between groups. A high ICC value means high variability between groups and low variability within groups. For example, if ICC $\mu$ is 0.2 , and ICC $v$ is 0.1 , we would say that $20 \%$ of the variation lies between firms, $10 \%$ lies between projects, and $70 \%$ lies between users (Leckie 2013). ICC values over 0.10 are indicators to perform a multi-level analysis (Snijders and Bosker 1999).

\subsection{Questionnaire design}

Three questionnaires were designed to obtain empirical data to test the influence of the factors identified on users' BIM adoption. The questionnaires were originally designed in English; however, they were translated into Spanish to reduce language bias (Harzing et al. 2009). To guarantee accuracy, the 
questionnaires were carefully translated by the first author of this paper, whose native language is Spanish. Survey items were identified from existing literature, with additional measurements purposively designed for this research. Questionnaire 1 (Q1) was designed for professionals representing their design and construction firms in BIM-enabled projects. Q1 had two sections. Section 1 included control questions such as profession, professional experience, and BIM experience. Section 2 included the measurement items on a five-point scale ( $1=$ Strongly Disagree, $5=$ Totally Agree $)$, adapted from Venkatesh et al. (2003) and Howard et al. (2017). However, 'BIM Adoption' was designed for this study, as shown in Table 3.

Table 3. Assessment items at the user level

\begin{tabular}{lll}
\hline User Level Factor & Variable & Assessment item \\
\hline $\begin{array}{l}\text { Performance expectancy } \\
\text { (PEXP) }\end{array}$ & PEXP1 & I find BIM useful for my work \\
& PEXP2 & Working in BIM enables me to accomplish tasks more quickly \\
Effort Expectancy (EEXP) & PEXP3 & Working in BIM increases my productivity \\
& EEXP1 & It is easy for me to become skilled at working with BIM \\
& EEXP2 & I find BIM easy to use \\
Social Influence (SINF) & SINF1 & Learning to use BIM is easy for me \\
& SINF2 & My boss thinks I should use BIM \\
& SINF3 & I use BIM because many of my co-workers use BIM \\
Facilitating Conditions & FCON1 & I have the software necessary to work with BIM \\
(FCON) & FCON2 & I have the training necessary to work with BIM \\
& FCON3 & A specific person is available for assistance with BIM difficulties \\
Behavioural Intention & BEHINT1 & I intend to use BIM as soon as possible \\
(BEHINT) & BEHINT2 & I intend to use BIM in the next project \\
& BEHINT3 & I have an intention to learn how to use BIM \\
BIM Adoption (BIMAD) & BIMAD1 & I use BIM in my job \\
& BIMAD2 & I collaborate with others in my organisations using BIM \\
& BIMAD3 & I collaborate with others outside my organisation using BIM \\
\hline
\end{tabular}

Questionnaire 2 (Q2) was designed for CEOs or senior executives with decision-making power. Q2 had two sections. Section 1 included control questions such as firm type, firm size, respondent's years of professional experience, and firm's years of experience with BIM. Section 2 included the measurement items on a five-point Likert Scale ( 1 = Strongly Disagree, $5=$ Totally Agree $)$, adapted from Venkatesh et al. (2003), Howard et al. (2017), and Parasuraman (2000). 'Firm's BIM Adoption' was also operationalised as a multi-item construct and was introduced for this study, as shown in Table 4. 
Table 4. Assessment items at the firm level

\begin{tabular}{lll}
\hline Firm-level Factor & Variable & Assessment item \\
\hline $\begin{array}{l}\text { Technology Readiness - } \\
\text { Optimism (FOPT) }\end{array}$ & FOPT1 & BIM will give the organisation more control over its operations \\
$\begin{array}{l}\text { Technology Readiness - } \\
\text { Innovativeness (FINNOVA) }\end{array}$ & FOPT2 & The organisation prefers to use the most advanced technology available \\
$\begin{array}{l}\text { Top-Management Support } \\
\text { (FTMS) }\end{array}$ & FINNOVA2 & Other organisations come to you for advice on how to implement BIM \\
& FTMS2 & I encourage my employees to use BIM \\
& FTMS3 & I recognise my employees' efforts to use BIM \\
$\begin{array}{ll}\text { Firm's Facilitating Conditions } \\
\text { (FFCON) }\end{array}$ & FFCON1 & The firm has the software necessary to work with BIM \\
& FFCON2 & The firm has provided training to staff to work with BIM \\
Firm's BIM Adoption & FFCON3 & There is a specific person available for assistance with BIM difficulties \\
(FBIMAD) & FBIMAD1 & The firm is actively using BIM \\
& FBIMAD2 & Employees collaborate with others using BIM within the organisation \\
& FBIMAD3 & Employees collaborate with others using BIM outside the organisation \\
\hline
\end{tabular}

Questionnaire 3 (Q3) was designed for project managers. The factors 'System Integrator', 'Diffusion Dynamic', 'Authorship of BIM Models', and 'Governance Mode' are nominal and were measured as dummy variables. 'System Integrator' options were 0: Client's project manager; and 1: Contractor. 'Diffusion Dynamic' options were 0: Client-led; and 1: Contractor-Led. 'Authorship of BIM Models' options were 0: In-house team; and 1: Outsourced consultant. 'Governance Mode' options were 0: Hierarchical (mandate); and 1: Co-learning (no BIM contracts).

The questionnaire also included a section to assess the technological capability of each firm participating in the project $(1=$ Very Low, 5 Very High). To construct a standardised measurement for 'Project-Coalition Technology Capability' (PTECH), we created a measure consisting of the summation of each firm's technology capability multiplied by the lowest technology capability as shown below. This indicator strengthens the effect of the digital disparity between firms by scaling the project's technology capability by the lowest capability.

$$
\text { PTECH }=\sum_{i=1}^{i=5} x_{i} * \min \left\{i_{1}, \ldots, i_{5}\right\} ; \text { where } x_{i} \text { is the ith firm's BIM technology capabilty }
$$

Similarly, the indicator 'Project-Coalition Collaboration Level' (PCOL) was calculated as shown below. This indicator strengthens the effect of the collaboration disparity between firms by scaling the project's collaboration level by the lowest level. 


$$
\text { PCOL }=\sum_{i=1}^{i=5} x_{i} * \min \left\{i_{1}, \ldots, i_{5}\right\} ; \text { where } x_{i} \text { is the ith firm's collaboration level }
$$

To standardise both indicators across projects, the following firms were considered: Architecture $(i=$ 1); Structural Engineering $(i=2)$; Mechanical and Electrical Engineering $(i=3)$; Plumbing Engineering $(i=4)$; and Contractor $(i=5)$.

\subsection{Research setting: the context of Peru}

Peru is located in the Latin American region and is considered a country with an upper-middle income economy (World Bank 2020). From anecdotal sources, BIM adoption in Peru dates back to 2010. A recent industry report found that $24.5 \%$ of building projects in Lima use BIM (Murguia et al. 2018). The study also found that the industry diffusion dynamic exhibits a middle-out approach (Succar and Kassem 2015) where large contractors started BIM adoption and therefore exerted pressures on other members of the supply chain (e.g. architects, engineers, and clients) to use BIM. At present, contractors are leading BIM adoption, whereas architects and engineers are behind.

With the success of the Pan American Games in Lima in 2019, where infrastructure was built in record time using BIM and collaborative contracts, a national BIM Steering Committee led by the Ministry of Economy has initiated a National BIM Plan for Public Projects. The Peruvian government has defined BIM as a collaborative methodology based on the use of digital models with the aim of centralising project information throughout the asset lifecycle. Peru is a representative country for understanding BIM adoption in a middle-out context, before top-down approaches are implemented by governments. Whilst acknowledging cultural differences, the findings of the model would be a valuable reference for other countries planning to implement a top-down approach to accelerate wider adoption.

\subsection{Data collection}

The questionnaires were piloted with 4 construction professionals, 2 CEOs of architectural practices, and 3 project managers. A few suggested revisions in the wording of assessment items, which were incorporated into the final questionnaire. The data were collected in Lima. The first author had access to influential organisations and industry partners leading BIM-enabled projects. The selection criteria were: (i) BIM adoption was led by the client/contractor at the project level; (ii) access to the list of design 
and construction firms and professionals working on these projects; and (iii) the project was under design or construction during data collection. First, 25 project managers were contacted to solicit project participants' contact details and to ask them to complete questionnaire Q1. In total, 20 project managers completed questionnaire Q1 (an $80 \%$ response rate). Second, 33 different firms were identified as working for these projects, with some firms working for one or more projects (thus confirming the crossclassified nature of the data). In total, 30 CEOs completed questionnaire Q2 (a 91\% response rate). Finally, a link to the online questionnaire was sent via email to 157 design and construction professionals working simultaneously for these firms and on these projects, and up to four reminders were sent every two weeks. As a result, 133 users completed questionnaire Q3 (an 85\% response rate). The demographic background of survey respondents is shown in Tables 5, 6, and 7 .

Table 5. Demographics of project managers and project characteristics

\begin{tabular}{llcc}
\hline Project-Level Variables & Value & Frequency & Percentage \\
\hline Project manager's years of & Less than 10 & 5 & 25.0 \\
experience & 11 to 15 & 8 & 40.0 \\
& 16 to 20 & 3 & 15.0 \\
Type of Project & More than 20 & 4 & 20.0 \\
& Commercial & 1 & 5.0 \\
& Hospital & 1 & 5.0 \\
& Sport Centre & 1 & 5.0 \\
& Educational & 2 & 10.0 \\
Owner & Hotel & 2 & 10.0 \\
Project Cost & Institutional & 2 & 10.0 \\
& Residential & 11 & 55.0 \\
& Private & 17 & 85.0 \\
& Public & 3 & 15.0 \\
& Less than 25M & 5 & 25.0 \\
& Between $26 \mathrm{M}$ and 50M & 5 & 25.0 \\
& Between 51M and 100M & 6 & 30.0 \\
& Between 101M and 300M & 2 & 10.0 \\
& More than 300M & 2 & 10.0 \\
\hline
\end{tabular}

Table 6. Demographics of CEOs/senior executives and firm characteristics

\begin{tabular}{llcc}
\hline Firm-Level Variables & Value & Frequency & Percentage \\
\hline Respondent & CEO & 18 & 60.0 \\
& Another Senior Executive & 12 & 40.0 \\
Respondent's years of & Less than 10 & 2 & 7.4 \\
experience & 11 to 15 & 6 & 22.2 \\
& 16 to 20 & 4 & 14.8 \\
Firm BIM Experience & More than 20 & 15 & 55.6 \\
& 1 to 2 years & 7 & 25.9
\end{tabular}




\begin{tabular}{llcc} 
& 3 to 4 years & 13 & 48.1 \\
\multirow{3}{*}{ Firm Type } & More than 5 years & 7 & 25.9 \\
& Contractor & 10 & 33.3 \\
\multirow{3}{*}{ Firm Size } & Designer & 20 & 66.7 \\
& Large & 4 & 13.3 \\
& Medium & 8 & 26.7 \\
& Small & 18 & 60.0 \\
\hline
\end{tabular}

Table 7. Demographics of design and construction professionals

\begin{tabular}{llcc}
\hline User-Level Variables & Value & Frequency & Percentage \\
\hline Profession & Construction & 60 & 42.3 \\
& Architect & 29 & 20.4 \\
& Structural Engineer & 27 & 19.0 \\
& MEP Engineer & 17 & 16.2 \\
& Other & 3 & 2.1 \\
Users' years of & 1 to 5 years & 35 & 26.3 \\
experience & 6 to 10 years & 46 & 34.6 \\
& 11 to 15 years & 30 & 22.6 \\
& More than 15 years & 22 & 16.5 \\
Users' BIM Experience & None & 28 & 21.1 \\
& 1 to 2 years & 67 & 50.4 \\
& 3 to 4 years & 29 & 21.8 \\
& More than 5 years & 9 & 6.8 \\
\hline
\end{tabular}

\section{Data analyses and results}

\subsection{Measurement validation}

First, it is necessary to assess the construct and discriminant validity of multi-item constructs. Construct validity is the extent to which a set of observed variables reflects the theoretical latent factor they are expected to measure (Hair et al. 2010). Construct validity is made up of convergent and discriminant validity components. Convergent validity can be evaluated by examining factor loadings, average variance extracted (AVE), and construct reliability (CR). Hair et al. (2010) recommend standardised factor-loading estimates above 0.5 and ideally above 0.7 . Similarly, an AVE of 0.5 or higher suggests adequate convergence. A CR above 0.7 suggests good reliability, whereas a CR between 0.6 and 0.7 might be acceptable if factor loadings and AVE are good (Hair et al. 2010).

The discriminant validity is the extent to which a latent factor is distinct from other latent factors. Fornell and Larcker (1981) recommend comparing the average variance extracted for any two constructs with 
the square of the estimated correlations between these two constructs. The average variance extracted should be greater than the squared correlation estimate.

\section{User level}

As indicated in Table 8, 13 factor loadings were above 0.70 and 4 factor loadings were above 0.50 . Thus, the first criterion for convergent validity was accepted. Second, 4 latent factors' composite reliabilities were above 0.70 and 2 above 0.60 . Therefore, the second criterion for convergent validity was accepted. Third, most AVEs are far above 0.50; however, since the AVE for 'Social Influence' was estimated at 0.44 and the AVE for 'Facilitating Conditions' was estimated at 0.36 , and all other indicators of convergent reliability were higher than the acceptable levels, the convergent validity of 'Social Influence' and 'Facilitating Conditions' was accepted. Furthermore, the correspondence between individual items and the latent factors was judged to be acceptable, as those scales were used in prior studies (Howard et al. 2017; Venkatesh et al. 2003). Overall, the convergent validity of the measurement model was accepted.

Table 8. Convergent Validity of Latent Factors - User Level

\begin{tabular}{llccc}
\hline Factor & $\begin{array}{l}\text { Observed } \\
\text { variables }\end{array}$ & $\begin{array}{c}\text { Factor } \\
\text { Loading }\end{array}$ & $\begin{array}{c}\text { Composite } \\
\text { Reliability }\end{array}$ & $\begin{array}{c}\text { Average } \\
\text { Variance } \\
\text { Extracted }\end{array}$ \\
\hline Performance expectancy & PEXP1 & 0.735 & 0.884 & 0.719 \\
(PEXP) & PEXP2 & 0.918 & & \\
Effort expectancy (EEXP) & PEXP3 & 0.880 & & \\
& EEXP1 & 0.785 & 0.881 & 0.713 \\
& EEXP2 & 0.861 & & \\
Social Influence (SINF) & EEXP3 & 0.884 & & \\
Facilitating Conditions (FCON) & SINF1 & 0.761 & 0.603 & 0.438 \\
& SINF2 & 0.545 & & \\
& FCON1 & 0.540 & 0.630 & 0.364 \\
Behavioural Intention & FCON2 & 0.692 & & \\
(BEHINT) & FCON3 & 0.568 & & 0.670 \\
& BEHINT1 & 0.858 & 0.858 & \\
BIM Adoption (BIMAD) & BEHINT2 & 0.929 & & 0.673 \\
& BEHINT3 & 0.728 & & \\
\hline & BIMAD1 & 0.833 & 0.859 & \\
& BIMAD2 & 0.929 & & \\
& BIMAD3 & 0.679 & & \\
\hline
\end{tabular}

All AVE estimates from Table 8 were greater than the corresponding square-correlation estimates in Table 9 (above the diagonal) except for the correlation between FCON and BIMP. However, the overall 
discriminant validity was accepted, as FCON was used in prior studies. Therefore, this test indicated that the discriminant validity for the measurement model was confirmed.

Table 9. Discriminant Validity of Latent Factors - User Level

\begin{tabular}{lcccccc}
\hline & PEXP & EEXP & SINF & FCON & BEHINT & BIMAD \\
\hline PEXP & 1.000 & 0.261 & 0.278 & 0.353 & 0.370 & 0.200 \\
EEXP & $0.511^{\mathrm{a}}$ & 1.000 & 0.227 & 0.437 & 0.221 & 0.112 \\
SINF & $0.527^{\mathrm{a}}$ & $0.476^{\mathrm{a}}$ & 1.000 & 0.381 & 0.408 & 0.127 \\
FCON & $0.594^{\mathrm{a}}$ & $0.661^{\mathrm{a}}$ & $0.617^{\mathrm{a}}$ & 1.000 & 0.316 & 0.473 \\
BEHINT & $0.609^{\mathrm{a}}$ & $0.470^{\mathrm{a}}$ & $0.639^{\mathrm{a}}$ & $0.562^{\mathrm{a}}$ & 1.000 & 0.242 \\
BIMAD & $0.447^{\mathrm{a}}$ & $0.334^{\mathrm{a}}$ & $0.357^{\mathrm{a}}$ & $0.688^{\mathrm{a}}$ & $0.492^{\mathrm{a}}$ & 1.000 \\
\hline
\end{tabular}

Note: Values below the diagonal are correlation estimates between constructs, and values above the diagonal are squared correlations; ${ }^{a} p<0.001$.

\section{Firm level}

A similar examination was conducted at the firm level, where multi-item constructs were also collected. As shown in Table 10, 'Technology Readiness - Optimism', 'Technology Readiness - Innovativeness', 'Top-Management Support', and 'Firm's BIM Adoption' exhibited acceptable values for convergent validity. However, 'Firm's Facilitating Conditions' showed an unacceptable convergent validity. This result demonstrated that FCON1 (software availability), FCON2 (training), and FCON3 (assistance) did not measure the same factor. Therefore, these variables were included separately in the model (FCON1 = FSOFT; FCON2 = FTRAIN; FCON3 = FASSIST), and hypothesis 11 was amended as follows:

H11a: 'BIM Software Availability' will have a significant influence on users' BIM adoption

H11b: 'Training to Employees' will have a significant influence on users' BIM adoption

H11c: 'BIM assistance to Employees' will have a significant influence on users' BIM adoption

Therefore, 'Firm's Facilitating Conditions' was dropped from the discriminant-validity assessment. All AVE estimates from Table 10 were greater than the corresponding square-correlation estimates in Table 11 (above the diagonal). Therefore, this test indicated that the discriminant validity for the measurement model was confirmed. 
Table 10. Convergent Validity of Latent Factors - Firm Level

\begin{tabular}{llccc}
\hline Factor & Variable & $\begin{array}{c}\text { Factor } \\
\text { Loading }\end{array}$ & $\begin{array}{c}\text { Composite } \\
\text { Reliability }\end{array}$ & $\begin{array}{c}\text { Average } \\
\text { Variance } \\
\text { Extracted }\end{array}$ \\
\hline Technology Readiness - & FOPT1 & 0.866 & 0.719 & 0.568 \\
Optimism (FOPT) & FOPT2 & 0.621 & & \\
Technology Readiness - & FINNOVA1 & 0.674 & 0.785 & 0.651 \\
Innovativeness (FINNOVA) & FINNOVA2 & 0.921 & & \\
Top-Management Support & FTMS1 & 0.863 & 0.811 & 0.595 \\
(FTMS) & FTMS2 & 0.584 & & \\
& FTMS3 & 0.837 & & \\
Firm's Facilitating Conditions & FFCON1 & 0.495 & 0.543 & 0.295 \\
(FFCON) & FFCON2 & 0.395 & & \\
& FFCON3 & 0.696 & & \\
Firm's BIM Adoption (FBIMAD) & FBIMAD1 & 0.872 & 0.924 & 0.802 \\
& FBIMAD2 & 0.971 & & \\
& FBIMAD3 & 0.839 & & \\
\hline
\end{tabular}

Table 11: Discriminant Validity of Latent Factors - Firm Level

\begin{tabular}{lcccc}
\hline & FOPT & FINNOVA & FTMS & FBIMAD \\
\hline FOPT & 1.000 & 0.356 & 0.392 & 0.187 \\
FINNOVA & $0.597^{\mathrm{a}}$ & 1.000 & 0.339 & 0.575 \\
FTMS & $0.626^{\mathrm{a}}$ & $0.582^{\mathrm{b}}$ & 1.000 & 0.360 \\
FBIMAD & $0.433^{\mathrm{c}}$ & $0.758^{\mathrm{a}}$ & $0.600^{\mathrm{a}}$ & 1.000 \\
\hline
\end{tabular}

Note: Values below the diagonal are correlation estimates between constructs, and values above the diagonal are squared correlations.

a $p<0.001$; $^{\mathrm{b}} \mathrm{p}<0.01$; $^{\mathrm{c}} \mathrm{p}<0.05$.

\section{Project level}

Table 12 shows the descriptive statistics for project-level variables, and Table 13 depicts the correlationanalysis results. A high correlation was observed between 'Diffusion Dynamic' and 'System Integrator' $(r=0.905 ; p<0.01)$. Therefore, it was decided to drop 'Diffusion Dynamic' from the analysis to avoid multicollinearity.

Table 12. Descriptive statistics of project-level variables

\begin{tabular}{lccccc}
\hline Project-Level Variables & N & Minimum & Maximum & Mean & S.D. \\
\hline System Integrator (PSYS) & 20 & 0.00 & 1.00 & 0.45 & 0.51 \\
Diffusion Dynamic (PDIFF) & 20 & 0.00 & 1.00 & 0.50 & 0.51 \\
Authorship of BIM Models (PAUT) & 20 & 0.00 & 1.00 & 0.60 & 0.50 \\
Governance Mode (PGOV) & 20 & 0.00 & 1.00 & 0.65 & 0.49 \\
Project-Coalition Technology Capability (PTECH) & 20 & 5.00 & 57.00 & 19.40 & 14.65 \\
Project-Coalition Collaboration Level (PCOL) & 20 & 7.00 & 125.00 & 40.30 & 33.31 \\
\hline
\end{tabular}


Table 13. Correlation matrix of project-level variables

\begin{tabular}{lcccccc}
\hline & PSYS & PDIFF & PAUT & PGOV & PTECH & PCOL \\
\hline PSYS & 1.000 & & & & & \\
PDIFF & $0.905^{\mathrm{b}}$ & 1.000 & & & & \\
PAUT & -0.287 & -0.408 & 1.000 & & & \\
PGOV & -0.390 & -0.314 & 0.043 & 1.000 & & \\
PTECH & 0.341 & 0.259 & 0.173 & -0.207 & 1.000 & \\
PCOL & 0.060 & -0.015 & $0.539^{c}$ & 0.020 & $0.636^{b}$ & 1.000 \\
\hline${ }^{a} p<0.001 ;{ }^{b} p<0.01 ;{ }^{c} p<0.05$. & & & & &
\end{tabular}

\subsection{Cross-classified structure validation}

Table 14 shows the variance composition of the null models in the single-level model (i.e. no clusters in the data) and the cross-classified model (i.e. data nested in firms and projects simultaneously). We can test the null hypothesis that there were no cluster differences at all by comparing the crossclassified model with the single-level model. The null and alternative hypothesis were written as:

$\mathrm{H}_{0}: \sigma_{\mu}^{2}=0, \sigma_{v}^{2}=0$ (no firm and project variation)

$H_{1}: \sigma_{\mu}^{2}>0, \sigma_{v}^{2}>0$ (significant firm and project variation)

Likelihood-ratio (LR) tests are used for testing the null hypothesis. The LR test statistic for testing the null hypothesis is calculated as: $L R=D_{0}-D_{1}$, where $D_{0}$ and $D_{1}$ are the deviance values for the singlelevel model and the cross-classified model, respectively. The LR statistics are then compared to a chisquared distribution with degrees of freedom equal to the number of extra parameters in the more complex model. In this case, the cross-classified model has two additional parameters $\left(\sigma_{\mu}^{2}, \sigma_{v}^{2}\right)$, so the degree of freedom is 2 . The LR of 57.80 with 2 degrees of freedom was significant at the $p=0.000$ level. Therefore, there was significant evidence to reject the null hypothesis and confirm that the crossclassified model fits the data better than a single-level model.

Table 14. Single-level null-model and cross-classified null-model results

\begin{tabular}{lllccc}
\hline & & \multicolumn{2}{c}{ Single-level model } & \multicolumn{2}{c}{ Cross-classified model } \\
\cline { 3 - 6 } & & Estimate & SE & Estimate & Posterior SD \\
\cline { 3 - 6 } $\boldsymbol{\beta}_{\boldsymbol{o}}$ & Intercept & $3.300^{\mathrm{a}}$ & 0.097 & $3.407^{\mathrm{a}}$ & 0.176 \\
$\boldsymbol{\sigma}_{v}^{2}$ & Project-level variance & - & - & $0.183^{\mathrm{a}}$ & 0.192 \\
$\boldsymbol{\sigma}_{\boldsymbol{\mu}}^{2}$ & Firm-level variance & - & - & $0.225^{\mathrm{a}}$ & 0.221 \\
$\boldsymbol{\sigma}_{\boldsymbol{\varepsilon}}^{2}$ & User-level variance & $1.326^{\mathrm{a}}$ & 0.157 & $0.930^{\mathrm{a}}$ & 0.142 \\
$\mathrm{D}$ & Deviance & 443.04 & - & 385.24 & - \\
$\mathrm{N}$ & Number of parameters & 2 & - & 4 & - \\
\hline
\end{tabular}

a $p<0.001$. 
The total variance was calculated as the sum of the three variance components $\sigma_{\varepsilon}^{2}+\sigma_{\mu}^{2}+\sigma_{v}^{2}$, which was estimated to be 1.338. We applied equations 1 and 2 to calculate the ICCs based on the estimated variances (Table 14). ICC $f$ and $I C C_{p}$ are estimated at 0.17 and 0.14 respectively. Because both between-firm and between-project ICCs were larger than 0.10 , the cross-classified multilevel model is appropriate for the data.

\subsection{Cross-classified multilevel model results}

The variables predicting users' BIM adoption were entered in the cross-classified model per analytical level, starting with the user-level factors (Model 1), followed by firm-level factors (Model 2), and finally project-level factors (Model 3). Such a process enabled the observation of the effect of each block of factors in the outcome-variable variance. Finally, a backwards deletion procedure was also conducted to keep significant factors only (Model 4) and to present a final MSBA.

Table 15 lists the cross-classified multilevel-model results. First, we ran Model 1. With the addition of user-level variables, the between-user level variance was reduced to $\sigma_{\varepsilon}^{2}=0.717$, suggesting that the variance at the individual level was attributable to differences between BIM users. Model 1 suggests that 'Behavioural Intention' and 'Facilitating Conditions' directly influence users' BIM adoption ( $\beta=0.312$, $p<0.001$ and $\beta=0.409, \quad p<0.001$ respectively). Additionally, 'Performance Expectancy', 'Effort Expectancy' and 'Social Influence' positively influence 'Behavioural Intention' $(\beta=0.393, p<0.001$; $\beta=0.157, p<0.05 ; \beta=0.265, p<0.001$ respectively).

When firm-level variables were added (Model 2$)$, the residual variances for the firm level $\left(\sigma_{\mu}^{2}=0.104\right)$ were reduced, indicating that a large portion of the firm-level variance was attributable to firm-level factors. The results showed that 'Firm Type' was significantly closer to the $5 \%$ level $(\beta=-0.555, p=0.061)$. Model 2 also suggests that 'Firm Size' did not significantly impact users' BIM adoption $(\beta=-0.442$, $p=0.165 ; \beta=-0.643, p=0.059$, for the dummy variables Small vs. Large and Medium vs. Large respectively). Thus, hypothesis 7 was not supported. 'Technology Readiness (optimism)' and 'Technology Readiness (innovativeness)' did not significantly influence users' BIM adoption ( $\beta=0.113$, $p=0.336$ and $\beta=0.136, p=0.217$, respectively). Hence, hypotheses 8 and 9 were not supported. There is a negative association between 'Top-Management Support' and 'BIM Adoption' ( $\beta=-0.873, p<0.001)$. Therefore, hypothesis 10 was supported. Additionally, there was an exceedingly weak influence of 'BIM 
Software Availability', 'Training to Employees', and 'BIM Assistance to Employees' on users' BIM adoption ( $\beta=0.002, \quad p=0.493 ; \quad \beta=0.000, p=0.500 ; \beta=0.046, p=0.386$, respectively). Therefore, hypotheses $11 \mathrm{a}, 11 \mathrm{~b}$, and $11 \mathrm{c}$ were not supported. Finally, the regression coefficient between 'Firm's BIM Adoption' and 'BIM Adoption' was not significant at the traditional $5 \%$ level $(\beta=0.249, p=0.106)$.

In Model 3, we added the project-level factors. The residual variances for the project level $\left(\sigma_{v}^{2}=0.081\right)$ were reduced, indicating that a large portion of the project-level variance was attributable to projectlevel factors. Although there is a positive regression coefficient for the effect of 'System Integrator' on users' BIM adoption $(\beta=0.430)$, it was not significant at the traditional $5 \%$ level $(p=0.078)$. This result is a weak suggestion that BIM users perform better in contractor-led projects than in client-led projects. The variable 'Authorship of BIM Models' was found to be significant at the $5 \%$ level $(\beta=-0.658, p=0.018)$, meaning that outsourced consultants negatively affect users' BIM adoption. The variables 'Governance Mode', 'Project-Coalition Technology Capability', and 'Project-Coalition Collaboration Level' were not found to be significant at the $5 \%$ level $(p=0.216, p=0.125$, and $p=0.317$ respectively). Therefore, hypotheses 16,17 and 18 were rejected.

Model 4 presents the results of the backward-deletion process in which insignificant predictors were dropped from the model one by one, starting with those with higher $p$-values. The results are shown in Table 16. At the user level, the results suggested that 'Behavioural Intention' and 'Facilitating Conditions' directly influence users' BIM adoption ( $\beta=0.377, p<0.001 ; \beta=0.374, p<0.001$ respectively). Thus, hypotheses 1 and 2 were accepted. Additionally, 'Performance Expectancy', 'Effort Expectancy' and 'Social Influence' positively influence 'Behavioural Intention' $(\beta=0.392, p<0.001 ; \beta=0.162, p<0.05$; $\beta=0.272, p<0.001$ respectively). Therefore, hypotheses 3,4 , and 5 were accepted. The explained variance for the systemic BIM diffusion model at the firm level was $\mathrm{R}^{2}=0.278$; therefore, $28 \%$ of the user level variation of BIM practice was explained by factors at the user level.

At the firm level, the results suggest that 'Firm Type' (Design vs. Contractor), 'Top-Management Support', and 'Firm's BIM Adoption' significantly influence BIM practice $(\beta=-0.558, p<0.01 ; \beta=-0.750$, $p<0.001$; and $\beta=0.422, p<0.01$, respectively). Therefore, hypotheses 6,10 , and 12 were supported. The explained variance for the systemic BIM diffusion model at the firm level was $R^{2}=0.751$; thus, $75 \%$ of the variation between firms in users' BIM adoption is explained by factors at the firm level. 
At the project level, the model suggests that between-project variation of 'Authorship of BIM Models' (Consultant vs. In-house) was found significantly to impact BIM practice $(\beta=-0.664, p<0.01)$. Thus, hypothesis 15 was supported. Additionally, 'Project-Coalition Technology Capability' positively influences 'Users' BIM Adoption' $(\beta=0.023, p<0.01)$. Therefore, hypothesis 18 was supported. The explained variance for the systemic BIM diffusion model at the project level was $R^{2}=0.503$; therefore $50 \%$ of the variation between projects in users' BIM adoption was explained by factors at the project level. 
Table 15. Cross-classified multilevel-model results

User Level

Dependent variable: Users' BIM Adoption (BIMAD)

Professional experience (years)

BIM Experience (years)

Behavioural intention

Facilitating Conditions

Dependent variable: Behavioural Intention

Performance Expectancy

Effort Expectancy

Social Influence

Firm Level

Dependent variable: Users' BIM Adoption (BIMAD)

Firm Type - Design (vs. Contractor)

Firm Size - Small (vs. Large)

Firm Size - Medium (vs. Large)

Technology readiness (optimism)

Technology readiness (innovativeness)

Top-Management Support

BIM Software availability

Training to employees

BIM assistance to employees

Firm's BIM Adoption

Project Level

Dependent variable: Users' BIM Adoption (BIMAD)

System Integrator - Contractor-Led (vs. Client-Led)

Authorship of BIM Models - Consultant (vs. In-house)

Governance Mode - Co-learning (vs. Mandate)

Project-Coalition Technology Capability

Project-Coalition Collaboration Level

Residual Variance (Users' BIM Adoption)

User Level $\boldsymbol{\sigma}_{\varepsilon}^{2}$

Firm Level $\boldsymbol{\sigma}_{\boldsymbol{\mu}}^{2}$

Project Lev $\boldsymbol{\sigma}_{v}^{2}$

$\mathrm{R}^{2}$ User level

$\mathrm{R}^{2}$ Firm level

$\mathrm{R}^{2}$ Project level

BIM adoption

\begin{tabular}{ccccc}
\hline Null Model & Model 1 & Model 2 & Model 3 & Model 4 \\
\hline & $\beta$ & $\beta$ & $\beta$ & $\beta$ \\
- & 0.010 & 0.008 & -0.001 & - \\
- & 0.043 & 0.055 & 0.062 & - \\
- & $0.312^{\mathrm{a}}$ & $0.370^{\mathrm{b}}$ & $0.365^{\mathrm{a}}$ & $0.377^{\mathrm{a}}$ \\
- & $0.409^{\mathrm{a}}$ & $0.341^{\mathrm{b}}$ & $0.322^{\mathrm{b}}$ & $0.374^{\mathrm{a}}$ \\
- & & & & \\
- & $0.393^{\mathrm{a}}$ & $0.392^{\mathrm{a}}$ & $0.392^{\mathrm{a}}$ & $0.392^{\mathrm{a}}$ \\
- & $0.157^{\mathrm{c}}$ & $0.160^{\mathrm{c}}$ & $0.158^{\mathrm{c}}$ & $0.162^{\mathrm{c}}$ \\
- & $0.265^{\mathrm{a}}$ & $0.275^{\mathrm{a}}$ & $0.276^{\mathrm{a}}$ & $0.272^{\mathrm{b}}$
\end{tabular}

$\begin{array}{ccc}-0.559^{d} & -0.514^{c} & -0.558^{b} \\ -0.442 & 0.192 & - \\ -0.643^{d} & -0.122 & - \\ 0.113 & 0.385 & - \\ 0.136 & 0.135 & - \\ -0.873^{a} & -0.771^{a} & -0.750^{a} \\ 0.002 & 0.002 & - \\ 0.000 & 0.027 & - \\ 0.046 & 0.014 & - \\ 0.249^{d} & 0.238 & 0.422^{b}\end{array}$

$0.430^{d}$

$-0.658^{c} \quad-0.664^{b}$

0.234

0.015

$0.023^{b}$

0.003

$\begin{array}{ccccc}0.930^{\mathrm{a}} & 0.717^{\mathrm{a}} & 0.698^{\mathrm{a}} & 0.674^{\mathrm{a}} & 0.671^{\mathrm{a}} \\ 0.225^{\mathrm{a}} & 0.180^{\mathrm{a}} & 0.104^{\mathrm{a}} & 0.102^{\mathrm{a}} & 0.056^{\mathrm{a}} \\ 0.183^{\mathrm{a}} & 0.170^{\mathrm{a}} & 0.158^{\mathrm{a}} & 0.081^{\mathrm{a}} & 0.091^{\mathrm{a}} \\ - & 0.229 & 0.249 & 0.275 & 0.278 \\ - & - & 0.538 & 0.547 & 0.751 \\ - & - & - & 0.557 & 0.503\end{array}$

Note: ${ }^{a} p<0.001 ;{ }^{b} p<0.01 ;{ }^{c} p<0.05 ;{ }^{d} p<0.10$. Unstandardised coefficients are reported. User-level sample size 133 (clustered in 30 firms and 20 projects) 
Table 16. Hypotheses testing results

\begin{tabular}{lll}
\hline Number & Hypothesis & Result \\
\hline $\mathrm{H} 1$ & 'Behavioural Intention' will have a significant influence on users' BIM adoption & Accepted \\
$\mathrm{H} 2$ & 'Facilitating Conditions' will have a significant influence on users' BIM adoption & Accepted \\
$\mathrm{H} 3$ & 'Performance Expectancy' will have a significant influence on 'Behavioural Intention' & Accepted \\
$\mathrm{H} 4$ & 'Effort Expectancy' will have a significant influence on 'Behavioural Intention' & Accepted \\
$\mathrm{H} 5$ & 'Social Influence' will have a significant influence on 'Behavioural Intention' & Accepted \\
$\mathrm{H} 6$ & 'Firm Type' will have a significant influence on users' BIM adoption & Accepted \\
$\mathrm{H} 7$ & 'Firm Size' will have a significant influence on users' BIM adoption & Rejected \\
$\mathrm{H} 8$ & 'Technology Readiness (optimism)' will have a significant influence on users' BIM adoption & Rejected \\
$\mathrm{H} 9$ & 'Technology Readiness (innovativeness)' will have a significant influence on users' BIM adoption & Rejected \\
$\mathrm{H} 10$ & 'Top-Management Support' will have a significant influence on users' BIM adoption & Accepted \\
$\mathrm{H} 11 \mathrm{a}$ & 'BIM Software Availability' will have a significant influence on users' BIM adoption & Rejected \\
$\mathrm{H} 11 \mathrm{~b}$ & 'Training to Employees' will have a significant influence on users' BIM adoption & Rejected \\
$\mathrm{H} 11 \mathrm{c}$ & 'BIM assistance to Employees' will have a significant influence on users' BIM adoption & Rejected \\
$\mathrm{H} 12$ & 'Firm's BIM Adoption' will have a significant influence on users' BIM adoption & Accepted \\
$\mathrm{H} 13$ & The 'System Integrator' will have a significant influence on users' BIM adoption & Rejected \\
$\mathrm{H} 14$ & The project's 'Diffusion Dynamic' will have a significant influence on users' BIM adoption & Rejected \\
$\mathrm{H} 15$ & The 'Authorship of BIM Models' will have a significant influence on users' BIM adoption & Accepted \\
$\mathrm{H} 16$ & The 'Governance Mode' will have a significant influence on users' BIM adoption & Rejected \\
$\mathrm{H} 17$ & The 'Project-Coalition Technology Capability' will have a significant influence on users' BIM adoption & Accepted \\
$\mathrm{H} 18$ & The 'Project-Coalition Collaboration Level' will have a significant influence on users' BIM adoption & Rejected \\
\hline
\end{tabular}

\section{Discussion}

\subsection{Theoretical contributions}

This study examined user, firm, and project factors that influence users' BIM adoption. At the user level, the MSBA showed that 'Behavioural Intention' directly influences users' BIM adoption. This result was consistent with Venkatesh et al. (2003) and Howard et al. (2017). The MSBA also confirmed the mediating role of 'Behavioural Intention' between 'Performance Expectancy' and users' BIM adoption. This result suggests that users who think that BIM will help to increase productivity and do a better job will have more incentives to use BIM. However, this result contradicts the results of Howard et al. (2017), who reported that there is no significant connection between 'Performance Expectancy' and 'Behavioural Intention'. Howard et al. (2017) also inquired about the characteristics that make BIM unique among information systems and argued that, since BIM is imposed at the organisational and project level, it is therefore perceived as an obstacle to completing tasks with no effect on their job performance. Addy et al. (2018) claimed that Ghanaian quantity surveyors do not regard BIM as important in improving productivity and are yet to comprehend the system's benefits. Nonetheless, this study has shown that design and construction professionals from this study have developed 
performance expectations to justify their intention to adopt BIM. This is in line with adoption studies in other developing countries such as China (Son et al. 2015; Xu et al. 2014).

'Effort Expectancy' was found positively to influence 'Behavioural Intention', meaning that users who think that BIM is easy to use will have a greater intention to use BIM in their projects. 'Effort Expectancy' has been found as a significant factor across contexts such as Australia (Bataresh et al. 2019; Sargent et al. 2012), the United Kingdom (Howard et al. 2017), Ghana (Addy et al. 2018), and China (Son et al. 2015; Xu et al. 2014). Similarly, 'Social Influence' had a positive influence on 'Behavioural Intention', meaning that users who think that using BIM makes the user more prestigious, both inside and outside the company, will have a greater intention to use BIM. Among the three factors influencing 'Behavioural Intention', 'Performance Expectancy' stood out as having the strongest influence on users' intentions towards BIM, followed by 'Social Influence' and 'Effort Expectancy'.

The present study also found that 'Facilitating Conditions' influences users' BIM adoption, which is consistent with theory (Howard et al. 2017; Sargent et al. 2012; Venkatesh et al. 2003). Hong et al. (2019a) found that 'Technical Support' is an important factor to BIM adoption in all types of firms regardless of their size and the project type delivered. 'Facilitating Conditions' encompasses BIM assistance to users. This suggests the need for an in-house BIM team or outsourced consultants working closely with users to foster BIM adoption. However, firm-level facilitating conditions (as stated by top managers) were not associated with users' BIM adoption. This finding reinforces the idea that there is an uneven distribution of software, hardware, training, and technical support among professionals within the firm other than BIM teams.

Contrary to the common belief, there exists a surprising negative relationship between 'TopManagement Support' and users' BIM adoption. This finding suggests that 'Top-Management Support' negatively influences the differences between firms in users' BIM adoption. This is counterintuitive and obviously contradicts previous research (Ahuja et al. 2016; Son et al. 2015; Wang and Song 2017). However, this finding might be interpreted as follows. Chief executives might see BIM as a commercial strategy to win contracts rather than a way to digitalise working processes and gain overall firm productivity. As such, BIM teams are created to lead BIM practices, but other professionals within the firm carry out traditional working practices and their adoption is slow. Since this study excluded responses from BIM teams, respondents' BIM adoption is lower than that of BIM team members. 
At the firm level, the model showed that 'Firm Type' (Design vs. Contractor) influences the difference between firms in users' BIM adoption. This result suggests that users working for construction firms perform better than users working for design firms. This is an important finding for contexts such as Peru, in which Tier 1 contractors have exerted pressures to use BIM on smaller firms - normally designers and subcontractors - within the supply chain. If public or private clients are to mandate BIM use, some strategies should be deployed to assure a seamless BIM diffusion within supply chains. For example, firms' BIM capability should be assured prior to the contract award. If contractors mandate BIM in the project, they should assume the role of system integrator in order to stimulate collaborative work between engineering consultants and construction teams.

Although differences in BIM adoption between SMEs and large engineering firms have been reported in major regions in China (Chen et al. 2019), this study did not find a significant impact of firm size on the differences between firms in users' BIM adoption. However, the difference could be attributed to the outcome variable in each study. Whereas Chen et al. (2019) studied adoption at the firm level, the present study investigated adoption at the user level. This result suggests that the collaborative process of model creation and federation led by the system integrator will allow users to engage with BIM practices due to mimetic pressures of larger firms. The model also showed that 'Firm's BIM Adoption' positively influences the differences between firms in users' BIM adoption. The high correlation of 'Firm's BIM Adoption' with 'Technology Readiness (Optimism)' ( $r=0.433, p<0.05)$ and 'Technology Readiness (Innovativeness)' $(r=0.758, p<0.001)$ suggests that firms with senior executives that understand BIM as a means to improve productivity and control over operations perform better than firms that use BIM only to meet client requirements.

At the project level, it was found that 'Authorship of BIM Models' was significant at the $1 \%$ level. This result suggests that users working on projects with in-house BIM teams perform better than users working on projects with outsourced BIM consultants. Similarly, the factor 'Project-Coalition Technology Capability' was also significant at the $1 \%$ level, meaning that the greater the project technology capability, the greater the users' adoption. Nevertheless, 'System Integrator' was not found to be significant at the $5 \%$ level $(p=0.11)$. Together, these three findings have several implications. First, regardless of the system integrator (contractor or client), in-house BIM teams positively influence users' BIM adoption. Second, firms with a low technology capability hinder user BIM adoption by other 
members of the project coalition. Therefore, the digital disparities have profound implications on systemic BIM adoption. Third, firms with low technology capability are not managing and exchanging their own 3D object-based models; however, system integrators have the authority to involve them in the collaborative process.

The 'Governance Mode' (Hierarchical vs. Co-learning) was not found to be a significant factor influencing the difference between projects in users' BIM adoption. Thus, there is no evidence to support that a hierarchical contractor- or client-led project (mandate) performs better than the co-learning project (no mandate). Therefore, a top-down approach would not be directly associated with users' BIM adoption, but creates the environment needed at the institutional level to promote users' and decisionmakers' acceptance of BIM.

\subsection{Managerial implications}

Systemic BIM adoption constitutes a radical shift in the digital delivery of the built environment which has significant implications in the way design, construction, and operation are organised. The model indicated that the majority of users' BIM adoption variance occurs at the user level. It is common to find that within BIM-enabled projects and firms, users are reluctant to embrace BIM. Nonetheless, BIM practice is fostered by 'Facilitating Conditions' which are entirely in the hands of decision-makers. Moreover, purposeful interventions on training could improve BIM users' 'Performance Expectancy', 'Effort Expectancy', and 'Social Influence'.

Firms should strike a balance between adoption driven by client/system integrator demand or adoption driven by internal productivity improvement and create a BIM strategy accordingly. For instance, inhouse BIM teams are created, or BIM authoring is outsourced. However, chief executives may argue that BIM will not reach its full potential due to the unreadiness of other partner firms or lack of client demand, thus making BIM an investment with a low return. The presence of outsourced consultants, however, creates a paradox in systemic BIM adoption. On the one hand, they are required to foster practice at the user level, especially in the early stages of the diffusion process. On the other hand, when consultants carry out BIM works, the BIM practice of design and construction professionals will decrease. Therefore, chief executives should carefully consider the extent of BIM outsourcing and the impact on users' practice, particularly for firms implementing it to control their operations. 
The model did not find a significant difference in BIM adoption between projects with client-led mandates and projects with a contractor-led co-learning environment. However, the model reflects that firms with low technology capability deepen the digital disparity within the project and negatively influence users' adoption. Asset owner operators and public agencies are commonly acknowledged as key drivers of BIM adoption. However, most clients are unaware or unwilling to adopt BIM. As such, contractor-led initiatives in the traditional, fragmented procurement system will only use BIM for specific needs (e.g. 3D modelling and clash detection after the designers have completed 2D drawings). Therefore, designers' BIM adoption will be lower than contractors' BIM adoption.

The model has helped to understand the critical role played by the system integrator to lead systemic BIM adoption at the project level. The industry might want to rethink the function of 'system integrator' or 'digital integrator' to lead integration as a deliverable to owners and operators (Whyte 2019). The role includes professional competence to assure information quality (clash-free models, buildable designs) and knowledge of the impact of design decisions on product quality, user satisfaction, cost, programme, and asset management. Systemic BIM adoption will require the adoption of more collaborative delivery methods such as 'Integrated Project Delivery' (Fischer et al. 2017) to allow system integrators to steer BIM implementation and engage firms with all levels of BIM capability early in the project.

The model would be particularly effective for policymakers planning to mandate BIM in construction. Charef et al. (2019) found that $25 \%$ of European countries have mandated BIM. Nonetheless, $50 \%$ are only planning to mandate and $25 \%$ do not have plans yet. Moreover, there are a growing number of governments in Latin America, in countries such as Mexico, Colombia, and Peru, that are working on BIM-adoption strategies for public construction. Furthermore, Kassem and Succar (2017) surveyed 21 countries, and 16 of those contexts exhibited the middle-out diffusion dynamic. Therefore, most countries develop BIM capabilities, led by large organisations, before adopting top-down approaches to maximise diffusion. Murguia (2019) found that the industry diffusion dynamic in Peru exhibited a middle-out approach where large contractors exert pressures on other members of the supply chain. Therefore, the findings of this study are an important contribution to the practicalities of systemic BIM adoption in the middle-out context. This may include practitioners and firms in a more developed context but not yet engaged with BIM. 


\section{Conclusions}

This study extends the body of knowledge of BIM diffusion by presenting a model of systemic BIM adoption that holistically combines factors at the user, firm, and project levels that explain users' BIM adoption. The model is particularly needed in a context where governments are planning to mandate BIM in construction. A model of systemic BIM adoption is a useful framework for policymakers to understand the BIM journey process and implement policies to accelerate wider adoption within supply chains. The model is effective in providing a richer picture of the determinants influencing BIM adoption in a system of firms and users working on BIM-enabled projects. Three original datasets consisting of 133 BIM users, 30 chief executive officers, and 20 project managers were collected in Peru and merged using cross-classified multilevel modelling (CCMM). CCMM has not been previously applied to investigate systemic adoption of innovations. The analysis of the empirical data has found that userlevel factors influencing BIM practice are 'Performance Expectancy', 'Effort Expectancy', 'Social Influence', 'Behavioural Intention', and 'Facilitating Conditions'. Additionally, the model has pinpointed the firm-level factors influencing the differences between firms in users' BIM adoption, namely, 'Firm Type', 'Top-Management Support', and 'Firm's BIM Adoption'. Finally, 'Authorship of BIM Models' and 'Project-Coalition Technology Capability' were found to be the most prominent factors at the project level explaining the differences between projects in users' BIM adoption. The data showed that $69 \%$ of users' BIM adoption variance occurs at the user level, whereas $17 \%$ and $14 \%$ of the variance happens at the firm and project levels, respectively. The model explains $28 \%, 75 \%$, and $50 \%$ of user-, firm-, and project-level variances, respectively.

First, 'Facilitating Conditions' was found to be a fundamental factor for users' BIM adoption. This userlevel factor is leveraged by top-management investment in BIM. To promote users' adoption, support and resources should be given to BIM teams and, more fundamentally, to the rest of the employees. Second, the model suggested that users working for construction firms perform better than users working in design firms, which is consistent with the middle-out diffusion context. Third, outsourced consultants are key players, as they aid to create BIM models and help system integrators to engage users with low BIM adoption. However, decision-makers should carefully consider the extent of BIM outsourcing and the impact on users' adoption, particularly for firms intending to control their operations. Fourth, firms with low BIM capability affect adoption of other project members. Fifth, the model has 
shown the critical role of system integrators as the driving force of systemic BIM adoption. Clients are required to lead system integration, request BIM use to their supply chain, and adopt new delivery models such as Integrated Project Delivery (IPD) to allow benefits in the project delivery as well as in asset management and performance. Therefore, traditional procurement routes would fail to sustain systemic BIM adoption.

This study has some limitations. First, the sample included design and construction firms. However, subcontractors and facility managers were not included. Further studies might investigate BIM practices of these actors within project coalitions. Second, the study is cross-sectional and does not capture different stages of innovation in users and firms. Third, results may not be directly replicable to different countries, as data were collected solely in Peru, a developing country planning a BIM mandate. However, the findings of this study can be a valuable reference for a context with a middle-out diffusion dynamic. Further research can be extended to projects with prevalent client-led initiatives and the examination of in-depth case studies to scrutinise the intra-firm and between-firm users' BIM adoption. Similar datasets could be collected in other countries to assess the presence and influence of cultural factors on systemic BIM adoption.

\section{Data-availability statement}

The data that support the findings of this study are openly available in Loughborough University's Repository at https://doi.org/10.17028/rd.lboro.11876535.v1.

\section{Acknowledgements}

This research was funded by the School of Architecture, Building, and Civil Engineering at Loughborough University, UK. The authors thank all survey respondents for their participation.

\section{References}

Addy, M., Adinyira, E., and Ayarkwa, J. (2018). "Antecedents of building information modelling adoption among quantity surveyors in Ghana: An application of a technology acceptance model." Journal of Engineering, Design and Technology, 16(2), 313-326.

Ahmed, A. L., and Kassem, M. (2018). "A unified BIM adoption taxonomy: Conceptual development, empirical validation and application." Automation in Construction, 96, 103-127.

Ahuja, R., Jain, M., Sawhney, A., and Arif, M. (2016). "Adoption of BIM by architectural firms in India: technology-organization-environment perspective." Architectural Engineering and Design 
Management, 12(4), 311-330.

Aksenova, G., Kiviniemi, A., Kocaturk, T., and Lejeune, A. (2019). "From Finnish AEC knowledge ecosystem to business ecosystem: lessons learned from the national deployment of BIM." Construction Management and Economics, 37(6), 317-335.

Arayici, Y., Coates, P., Koskela, L., Kagioglou, M., Usher, C., and O'Reilly, K. (2011). "Technology adoption in the BIM implementation for lean architectural practice." Automation in Construction, Elsevier B.V., 20(2), 189-195.

Ayinla, K. O., and Adamu, Z. (2018). "Bridging the digital divide gap in BIM technology adoption." Engineering, Construction and Architectural Management, 25(10), 1398-1416.

Bataresh, S., Kamardeen, I., and Mojtahedi, M. (2019). "Extrinsic and Intrinsic Drivers of BIM Adoption in the Australian AEC Industry." Proceedings of the 43rd Australasian Universities Building Education Association Conference, 684-693.

Bosch-Sijtsema, P., Isaksson, A., Lennartsson, M., and Linderoth, H. C. J. (2017). "Barriers and facilitators for BIM use among Swedish medium-sized contractors - 'We wait until someone tells us to use it." Visualization in Engineering, Visualization in Engineering, 5(1), 1-12.

Cao, D., Li, H., and Wang, G. (2014). "Impacts of isomorphic pressures on BIM adoption in construction projects." Journal of Construction Engineering and Management, 140(12), 04014056.

Cao, D., Li, H., Wang, G., and Huang, T. (2017). "Identifying and contextualising the motivations for BIM implementation in construction projectsAn empirical study in China." International Journal of Project Management, 35(4), 658-669.

Cao, D., Li, H., Wang, G., and Zhang, W. (2016). "Linking the Motivations and Practices of Design Organizations to Implement Building Information Modeling in Construction Projects: Empirical Study in China." Journal of Management in Engineering, 32(6), 1-10.

Charef, R., Emmitt, S., Alaka, H., and Fouchal, F. (2019). "Building Information Modelling adoption in the European Union: An overview." Journal of Building Engineering, 25, 100777.

Chen, Y., Yin, Y., Browne, G. J., and Li, D. (2019). "Adoption of building information modeling in Chinese construction industry: The technology-organization-environment framework." Engineering, Construction and Architectural Management.

Dainty, A., Leiringer, R., Fernie, S., and Harty, C. (2017). "BIM and the small construction firm: a critical perspective." Building Research and Information, 45(6), 696-709.

Davies, R., Crespin-Mazet, F., Linné, A.., Pardo, C., Havenvid, M. I., Harty, C., Ivory, C., and Salle, R. (2015). "BIM in Europe: Innovation networks in the construction sectors of Sweden, France and the UK." Association of Researchers in Construction Management, ARCOM 2015 - Proceedings of the 31st Annual Conference, 1135-1144.

Davies, R., and Harty, C. (2013). "Measurement and exploration of individual beliefs about the consequences of building information modelling use." Construction Management and Economics, 31(11), 1110-1127.

Ding, Z., Zuo, J., Wu, J., and Wang, J. Y. (2015). "Key factors for the BIM adoption by architects: A China study." Engineering, Construction and Architectural Management, 22(6), 732-748.

Eadie, R., Browne, M., Odeyinka, H., Mc keown, C., and Mc niff, S. (2015). "A survey of current status of and perceived changes required for BIM adoption in the UK." Built Environment Project and Asset Management, 5(1), 4-21.

Eadie, R., Browne, M., Odeyinka, H., McKeown, C., and McNiff, S. (2013). "BIM implementation throughout the UK construction project lifecycle: An analysis." Automation in Construction, Elsevier B.V., 36, 145-151. 
Elmualim, A., and Gilder, J. (2014). "BIM: Innovation in design management, influence and challenges of implementation." Architectural Engineering and Design Management, 10(3-4), 183-199.

Enegbuma, W. I., Aliagha, G. U., Ali, K. N., and Badiru, Y. Y. (2016). "Confirmatory strategic information technology implementation for building information modelling adoption model." Journal of Construction in Developing Countries, 21(2), 113-129.

Erbil, Y., Akincitürk, N., and Acar, E. (2013). "Inter-organizational context of the innovation process and the role of architectural designers as system integrators: Case evidence from Turkey." Architectural Engineering and Design Management, 9(2), 77-94.

Fischer, M., Ashcraft, H., Reed, D., and Khanzode, A. (2017). Integrating Project Delivery. Integrating Project Delivery, John Wiley \& Sons, Inc., New Jersey.

Fornell, C., and Larcker, D. F. (1981). "Evaluating Structural Equation Models with Unobservable Variables and Measurement Error." Journal of Marketing Research, 18(1), 39-50.

Foroozanfar, M., Sepasgozar, S. M. E., and Arbabi, H. (2017). "An empirical investigation on construction companies' readiness for adopting sustainable technology." ISARC 2017 Proceedings of the 34th International Symposium on Automation and Robotics in Construction, (Isarc), 925-936.

Fountain, J., and Langar, S. (2018). "Building Information Modeling (BIM) outsourcing among general contractors." Automation in Construction, 95, 107-117.

Franz, B., and Messner, J. (2019). "Evaluating the Impact of Building Information Modeling on Project Performance." Journal of Computing in Civil Engineering, 33(3), 1-9.

Gong, P., Zeng, N., Ye, K., and König, M. (2019). "An Empirical Study on the Acceptance of 4D BIM in EPC Projects in China." Sustainability (Switzerland), 11(5), 1-19.

Gu, N., and London, K. (2010). "Understanding and facilitating BIM adoption in the AEC industry." Automation in Construction, 19, 988-999.

Hair, J., Black, W., Babin, B., and Anderson, R. (2010). "Multivariate Data Analysis: A Global Perspective." Multivariate Data Analysis: A Global Perspective.

Hall, D. M., Algiers, A., and Levitt, R. E. (2018). "Identifying the Role of Supply Chain Integration Practices in the Adoption of Systemic Innovations." Journal of Management in Engineering, 34(6), 04018030.

Harty, C. (2008). "Implementing innovation in construction: Contexts, relative boundedness and actornetwork theory." Construction Management and Economics, 26(10), 1029-1041.

Harzing, A. W., Baldueza, J., Barner-Rasmussen, W., Barzantny, C., Canabal, A., Davila, A., Espejo, A., Ferreira, R., Giroud, A., Koester, K., Liang, Y. K., Mockaitis, A., Morley, M. J., Myloni, B., Odusanya, J. O. T., O'Sullivan, S. L., Palaniappan, A. K., Prochno, P., Choudhury, S. R., SakaHelmhout, A., Siengthai, S., Viswat, L., Soydas, A. U., and Zander, L. (2009). "Rating versus ranking: What is the best way to reduce response and language bias in cross-national research?" International Business Review, 18, 417-432.

Hong, Y., Hammad, A. W. A., and Akbarnezhad, A. (2019a). "Impact of organization size and project type on BIM adoption in the Chinese construction market." Construction Management and Economics, Routledge, 37(11), 675-691.

Hong, Y., Hammad, A. W. A., Sepasgozar, S., and Akbarnezhad, A. (2019b). "BIM adoption model for small and medium construction organisations in Australia." Engineering, Construction and Architectural Management, 26(2), 154-183.

Hosseini, M. R., Banihashemi, S., Chileshe, N., Oraee Namzadi, M., Udaeja, C., Rameezdeen, R., and McCuen, T. (2016). "BIM adoption within Australian Small and Medium-sized Enterprises (SMEs): an innovation diffusion model." Construction Economics \& Building, 16(3), 71-86. 
Howard, R., Restrepo, L., and Chang, C.-Y. (2017). "Addressing individual perceptions: An application of the unified theory of acceptance and use of technology to building information modelling." International Journal of Project Management, 35(2), 107-120.

Jin, R., Hancock, C., Tang, L., Chen, C., Wanatowski, D., and Yang, L. (2017). "Empirical Study of BIM Implementation-Based Perceptions among Chinese Practitioners." Journal of Management in Engineering, 33(5), 04017025.

Kassem, M., and Succar, B. (2017). "Macro BIM adoption: Comparative market analysis." Automation in Construction, 81, 286-299.

Keast, R., and Hampson, K. (2007). "Building constructive innovation networks: Role of relationship management." Journal of Construction Engineering and Management, 133(5), 364-373.

Kim, S., Park, C. H., and Chin, S. (2016). "Assessment of BIM acceptance degree of Korean AEC participants." KSCE Journal of Civil Engineering, 20(4), 1163-1177.

Leckie, G. (2013). “Cross-Classified Multilevel Models. LEMMA VLE Module 12.” Bristol.

Lee, S., and Yu, J. (2016). "Comparative Study of BIM Acceptance between Korea and the United States." Journal of Construction Engineering and Management, 142(3), 05015016.

Lee, S., Yu, J., and Jeong, D. (2015). "BIM Acceptance Model in Construction Organizations." Journal of Management in Engineering, 31(3), 04014048.

Liljander, V., Gillberg, F., Gummerus, J., and van Riel, A. (2006). "Technology readiness and the evaluation and adoption of self-service technologies." Journal of Retailing and Consumer Services, 13(3), 177-191.

Lindblad, H., and Guerrero, J. R. (2020). "Client's role in promoting BIM implementation and innovation in construction." Construction Management and Economics, Routledge, 1-15.

Lindblad, H., and Gustavsson, T. K. (2018). "Project managers as involuntary policy implementers? The case of implementing BIM." Association of Researchers in Construction Management, ARCOM 2018 - Proceedings of the 34th Annual Conference, (September), 465-474.

Linderoth, H. C. J. (2010). "Understanding adoption and use of BIM as the creation of actor networks." Automation in Construction, Elsevier B.V., 19(1), 66-72.

Lindgren, J., and Emmitt, S. (2017). "Diffusion of a systemic innovation A longitudinal case study of a Swedish multi-storey timber housebuilding system." Construction Innovation, 17(1), 25-44.

Lindgren, J., and Widén, K. (2018). "Diffusing building information management-knowledge integration, mechanisms and knowledge development." Architectural Engineering and Design Management, Taylor \& Francis, 14(5), 347-362.

London, K., Singh, V., Taylor, C., Gu, N., and Brankovic, L. (2008). "Building Information Modelling project decision support framework." Association of Researchers in Construction Management, ARCOM 2008 - Proceedings of the 24th Annual Conference, 665-673.

Mahamadu, A. M., Mahdjoubi, L., and Booth, C. A. (2017). "Critical BIM qualification criteria for construction pre-qualification and selection." Architectural Engineering and Design Management, Taylor \& Francis, 13(5), 326-343.

Mahamadu, A. M., Mahdjoubi, L., Booth, C., Manu, P., and Manu, E. (2019). "Building information modelling (BIM) capability and delivery success on construction projects." Construction Innovation, 19(2), 170-192.

Manderson, A., Jefferies, M., and Brewer, G. (2015). "Building information modelling and standardised construction contracts: A content analysis of the GC21 contract." Construction Economics and Building, 15(3), 72-84.

Murguia, D. (2019). 2019 Macro BIM Adoption Study in Peru. Lima, Peru. 
Murguia, D., Demian, P., and Soeatanto, R. (2017). "A Systemic BIM Innovation Model in the Construction Supply Chain." Association of Researchers in Construction Management, ARCOM 2017 - Proceedings of the 33rd Annual Conference, 15-24.

Murguia, D., Tapia, G., and Collantes, J. (2018). 2018 BIM Adoption Survey in Lima and Callao.

Murphy, M. E. (2014). "Implementing innovation: A stakeholder competency-based approach for BIM." Construction Innovation, 14(4), 433-452.

Ngowtanasawan, G. (2017). "A Causal Model of BIM Adoption in the Thai Architectural and Engineering Design Industry." Procedia Engineering, 180, 793-803.

Okakpu, A., GhaffarianHoseini, A., Tookey, J., Haar, J., and Ghaffarianhoseini, A. (2019). "Exploring the environmental influence on BIM adoption for refurbishment project using structural equation modelling." Architectural Engineering and Design Management, 16(1), 41-57.

Ozorhon, B., and Karahan, U. (2017). "Critical Success Factors for Building Information Modelling Implementation." Journal of Management in Engineering, 33(3), 04016054.

Parasuraman, A. (2000). "Technology Readiness Index (Tri): A Multiple-Item Scale to Measure Readiness to Embrace New Technologies." Journal of Service Research, 2(4), 307-320.

Park, E., Kwon, S. J., and Han, J. (2019). "Antecedents of the adoption of building information modeling technology in Korea." Engineering, Construction and Architectural Management, 26(8), 17351749 .

Peansupap, V., and Walker, D. (2005). "Exploratory factors influencing information and communication technology diffusion and adoption within Australian construction organizations: a micro analysis." Construction Innovation, 5(3), 135-157.

Poirier, E., Staub-French, S., and Forgues, D. (2015). "Embedded contexts of innovation: BIM adoption and implementation for a specialty contracting SME." Construction Innovation, 15(1), 42-65.

Renier, B., and Volker, L. (2008). "The architect as a system integrator?" Association of Researchers in Construction Management, ARCOM 2008 - Proceedings of the 24th Annual Conference, 125134.

Sargent, K., Hyland, P., and Sawang, S. (2012). "Factors Influencing the Adoption of Information Technology in a Construction Business." Australasian Journal of Construction Economics and Building, 12, 72-86.

Singh, V. (2014). "BIM and systemic ICT innovation in AEC." Construction Innovation, Emerald Group Publishing Limited, 14(3), 292-306.

Slaughter, E. (1998). "Models of Construction Innovation." Journal of Construction Engineering and Management, 124(3), 226-231.

Snijders, T. A. B., and Bosker, R. J. (1999). Multilevel analysis: An introduction to basic and advanced multilevel modeling. SAGE Publications Ltd, London.

Son, H., Lee, S., and Kim, C. (2015). "What drives the adoption of building information modeling in design organizations? An empirical investigation of the antecedents affecting architects' behavioral intentions." Automation in Construction, 49, 92-99.

Taylor, J., and Levitt, R. (2004). "Understanding and managing systemic innovation in project-based industries." Innovations: Project Management Research 2004, Newton Square, PA: Project Management Institute, 83-99.

Venkatesh, V., Morris, M. G., Davis, G. B., and Davis, F. D. (2003). "User acceptance of information technology: Toward a unified view." MIS Quarterly: Management Information Systems, 27(3), 425-478.

Wang, G., and Song, J. (2017). "The relation of perceived benefits and organizational supports to user 
satisfaction with building information model (BIM)." Computers in Human Behavior, 68, 493-500.

Whyte, J. (2019). "How Digital Information Transforms Project Delivery Models." Project Management Journal, 50(2), 177-194.

World Bank. (2020). "World Bank Country and Lending Groups." <https://datahelpdesk.worldbank.org/knowledgebase/articles/906519-world-bank-country-andlending-groups> (Jun. 17, 2019).

$\mathrm{Xu}, \mathrm{H}$., Feng, J., and Li, S. (2014). "Users-orientated evaluation of building information model in the Chinese construction industry." Automation in Construction, 39, 32-46. 